\title{
Vicuñas y humanos en el pasado reciente (siglos XIX y XX) del oeste tinogasteño (Catamarca, Argentina)
}

\author{
Juan Pablo Miyano ${ }^{*}$, Norma Ratto ${ }^{* *}$ \\ Instituto de las Culturas, Universidad de Buenos Aires, Consejo Nacional \\ de Investigaciones Científicas y Técnicas (Conicet), Argentina
}

Vicuñas and Humans in the Recent Past (Nineteenth and Twentieth Centuries) of Western Tinogasta (Catamarca, Argentina)

D0I: $10.22380 / 2539472 X .632$

\begin{abstract}
$\overline{\text { RESUMEN }}$
Este trabajo explora la percepción sobre las vicuñas de los pobladores del oeste tinogasteño (Catamarca, Argentina) del pasado reciente (siglos XIX y XX). Para ello se analizan las manifestaciones orales tradicionales recopiladas en la Colección de Folklore que corresponden a distintas localidades de la región de estudio ( $\mathrm{La}$ Ramadita, Medanitos y Fiambalá). Los resultados se integran y discuten con los sistemas simbólicos de la cosmovisión andina, la información proveniente de fuentes orales y escritas de otros sectores de los Andes centro-sur y la información arqueológica y zooarqueológica del oeste tinogasteño que da cuenta de la relación humano-animal entre los siglos V a. C. y XV d. C.
\end{abstract}

Palabras claves: vicuñas, etnozoología, cosmovisión andina, cultura popular.

\begin{abstract}
This paper examines the perception of the vicuñas by the habitants of western Tinogasta (Catamar$\mathrm{ca}$, Argentina) during the recent past (Nineteenth and Twentieth Centuries). For this purpose, we analyzed traditional oral manifestations compiled in the Colección de Folklore belonging to different localities of the region of study (La Ramadita, Medanitos y Fiambalá). The results were integrated and discussed with the symbolic systems of the Andean cosmovision, information from oral and written sources of other sectors of the south-central Andes, and archaeological and zooarchaeological information of the western Tinogasta, which accounts for human-animal relationships during the $V B C$ and XV AD centuries.
\end{abstract}

Keywords: vicuñas, Ethnozoology, Andean cosmovision, popular culture.

jpmiyano@gmail.com / https://orcid.org/0000-0001-8752-8614

nratto@filo.uba.ar / https://orcid.org/0000-0002-6862-3330 


\section{Introducción}

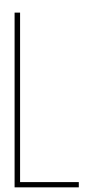

a etnozoología estudia la manera en que los seres humanos conciben, clasifican, representan y se relacionan con los animales dentro de un marco espacial-temporal determinado (Costa, Vargas y Santos 2009a). Todas las sociedades otorgan a los animales valores tangibles - relacionados con los diversos recursos que pueden ofrecer o funciones que pueden cumplir - e intangibles - vinculados con los lugares que ocupan dentro de los esquemas simbólicos y la cosmovisión- (Santos, Costa y Cano-Contreras 2009). Sin embargo, no todos los animales son valorados del mismo modo: mientras algunos son destacados, otros son incluidos en categorías genéricas, en tanto que unos son ignorados (Grebe 1984).

La comprensión de la cosmovisión de las sociedades es clave para los estudios etnozoológicos dado que condiciona la relación humano-animal. La cosmovisión presenta un carácter instrumental: los sistemas ideológico-simbólicos que la componen son una guía para los seres humanos, tanto para la percepción del mundo como para la acción y el desarrollo de prácticas, diferenciando conductas esperables e impropias. Las primeras sostienen y reproducen el orden y el equilibrio social; las segundas son disruptivas y entran en contradicción con los principios de la cosmovisión. Asimismo, la cosmovisión no es inmutable sino que se encuentra en permanente actualización y transformación, ya sea por el desarrollo interno de cada grupo humano o por la incorporación de elementos externos a él (Cano-Contreras 2009). Así, el mismo animal puede ser valorado de manera diferente en un mismo contexto espacial a lo largo del tiempo o de diferentes formas por diversos sectores de la sociedad en un mismo momento. En suma, los estudios etnozoológicos deben considerar la cosmovisión dado que “cualquier relación (utilitaria, simbólica o cognitiva) que se establezca entre el ser humano y los animales estará invariablemente determinada por su cosmovisión” (Cano-Contreras 2009, 64).

La etnozoología es interdisciplinaria, ya que la antropología, la historia, el folclor y la zooarqueología pueden contribuir a dar cuenta de la relación entre el humano y el animal (Santos, Costa y Cano-Contreras 2009). Dichas disciplinas utilizan distintos tipos de fuentes de información, sus alcances no coinciden necesariamente y pueden complementarse. La zooarqueología aporta 
información sobre la subsistencia en el pasado, el uso de los recursos animales y las estrategias empleadas en su captura o manejo, entre otras. Sin embargo, el mero análisis zooarqueológico no permite profundizar en las valoraciones otorgadas a los animales (exceptuando ciertos contextos arqueológicos como los funerarios y rituales). Así, la historia, la antropología y el folclor permiten aproximarnos a aquellos aspectos que desde la zooarqueología resulta difícil estudiar. Puesto que el alcance de las tres se circunscribe al presente y a un pasado relativamente reciente en comparación con la profundidad temporal de la zooarqueología, estas disciplinas pueden complementarse para estudiar cambios o continuidades en la relación humano-animal, en una región determinada y en una escala temporal amplia.

Las manifestaciones folclóricas (creencias, mitos, fábulas, leyendas, juegos, entre otras) se constituyen como un aspecto de la investigación etnozoológica ya que ofrecen información de la relación humano-animal y de la cosmovisión de un grupo humano en un contexto espacial y temporal particular (Santos, Costa y Cano-Contreras 2009). Si bien dichas manifestaciones se caracterizan por provenir del pasado, tienen vigencia en el presente, rigiendo actos y estableciendo pautas de conducta (Cortázar 1959).

Con base en lo expuesto, este trabajo aborda la percepción y valoración de la vicuña entre los habitantes del oeste tinogasteño (Catamarca, Argentina) durante los siglos XIX y XX, a partir del análisis de las manifestaciones orales tradicionales de la Colección de Folklore. Esta obra consiste en una recopilación de la cultura popular (creencias, mitos, fábulas, etc.), impulsada por el Consejo Nacional de Educación argentino en 1921 y realizada en todo el país. Esta información se relaciona con datos históricos, arqueológicos y zooarqueológicos regionales y extrarregionales para discutir la relación entre el humano y la vicuña desde los tiempos de las sociedades agropastoriles prehispánicas hasta los siglos XIX y XX. Se evalúan tres aspectos vinculados a las vicuñas: a) la organización social y el uso del espacio en torno a su captura; b) su valor tangible; y c) su valor intangible. Como hipótesis se sostiene que, durante el pasado reciente del oeste tinogasteño (siglos XIX y XX), la percepción y la valoración humana de la vicuña se encontró enmarcada dentro de los sistemas ideológico-simbólicos que estructuran la cosmovisión andina, y su uso y aprovechamiento respondieron a modalidades empleadas durante momentos prehispánicos. 
Figura 1. Vicuñas en Las Peladas (puna transicional de Chaschuil, Catamarca, 3.940 m s. n. m.)

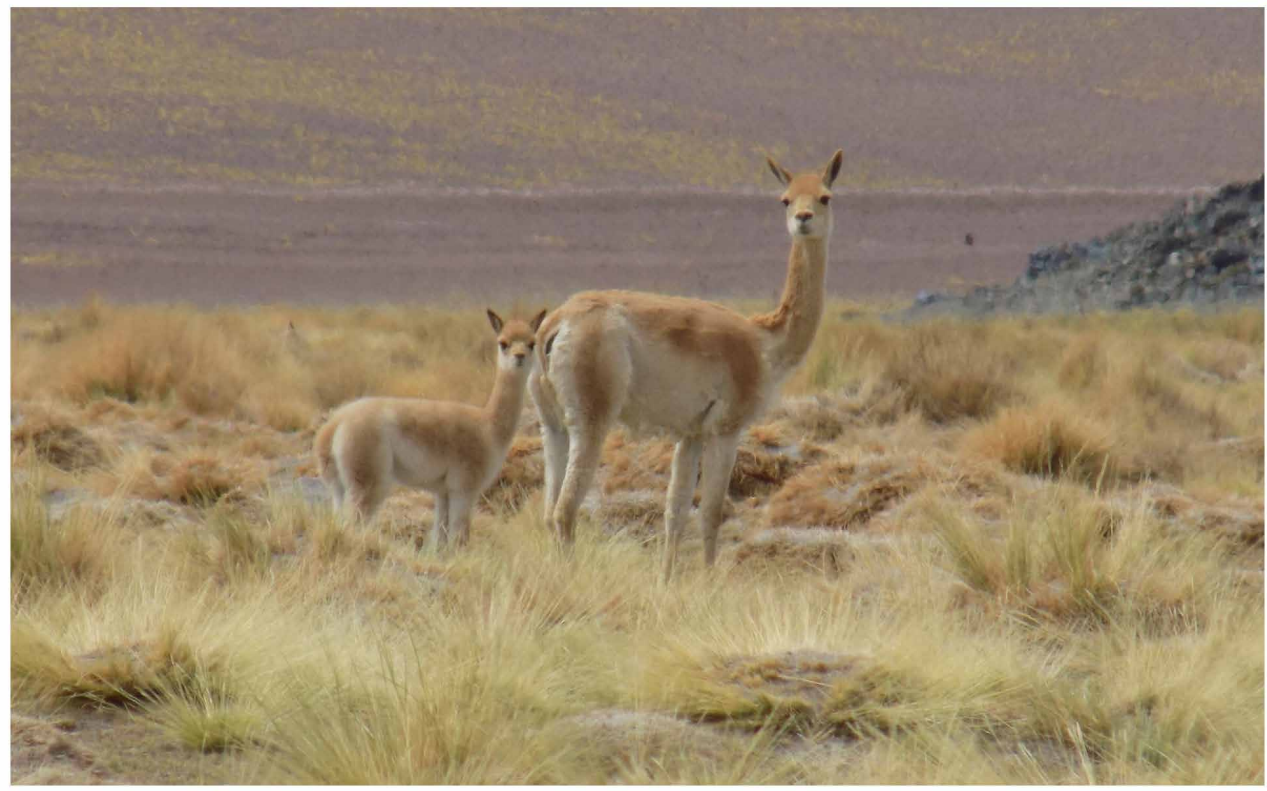

Fuente: fotografía de Juan Pablo Miyano.

\section{Antecedentes: la relación humano-vicuña en el noroeste argentino a través del tiempo}

La vicuña (Vicugna vicugna) es una especie silvestre de la familia Camelidae (figura 1). Su hábitat se acota a las provincias biogeográficas Puneña y Altoandina (ca. 3.500-4.800 m s. n. m.) en Perú, Bolivia, Chile y Argentina. Se trata de un animal gregario y territorial que se organiza principalmente en grupos familiares y grupos de solteros. Los grupos familiares (un macho, tres a cuatro hembras y dos crías) tienen un territorio que no supera las 30 ha, dentro de las que se incluyen zonas de descanso, áreas de alimentación y fuentes de agua. Los grupos de solteros (de composición numerosa, variable e inestable) buscan machos de grupos familiares para desafiar, hembras para reproducirse y territorios para dominar (Franklin 1982; Vilá 2012).

Los camélidos sudamericanos fueron clave para las sociedades andinas prehispánicas, desde las primeras cazadoras recolectoras ( $c a .11 .000$ años a. P.) hasta el dominio incaico de gran parte de la región (ca. 500-600 años a. P.) 
(Mengoni 2008). Las vicuñas fueron aprovechadas no solo por sus recursos nutricionales sino también por su fibra, cueros y huesos (Yacobaccio 2009). En el noroeste argentino, la relación humano-vicuña se inicia con las primeras sociedades cazadoras recolectoras (11.000-8500 años a. P.). La intensificación en la caza de camélidos entre los 8500-5300 años a. P. marca el inicio del proceso de domesticación de uno de ellos: el guanaco. Así, la aparición de la llama (ca. 46003000 años a. P.) supuso un cambio en estas sociedades dada la incorporación del componente pastoril a la subsistencia (Mengoni 2008).

Después de los 3000-2500 años a. P. se consolidó el modo de vida agropastoril y el sistema de asentamiento se organizó en torno a la agricultura y el pastoreo (Olivera 2001). Sin embargo, la caza de vicuñas continuó practicándose, posiblemente por los pastores durante sus ciclos de movilidad trashumante (Olivera y Grant 2009; Yacobaccio 2009). La presencia de restos de vicuña en sitios arqueológicos valliserranos (Izeta 2008) sugiere la interacción de los habitantes de dicha región con la puna, ya sea de manera directa o indirecta.

Hacia los ca. 500-600 años a. P., el actual noroeste argentino fue incorporado dentro del imperio incaico. Las crónicas del periodo de contacto hispanoindígena indican que la captura de vicuñas dentro de los límites imperiales se encontraba regulada y se realizaba mediante cacerías comunales (e.g. chaku), junto con el encierro de varios animales, la matanza selectiva de algunos y la esquila y liberación del resto (Ratto y Orgaz 2002-2004, 2008; Yacobaccio 2009).

Tras la Conquista española, la vicuña continuó siendo cazada tanto para el aprovechamiento local como para la exportación de su fibra a Europa, lo cual creó una fuerte presión sobre la especie. Este escenario se profundizó en el periodo republicano: hacia mediados del siglo $\mathrm{XX}$, la población de vicuñas se redujo drásticamente dada su matanza indiscriminada, fenómeno de todo el altiplano andino (Vilá 2012; Yacobaccio 2009). Desde la década de 1960, diversas políticas de protección y conservación permitieron la recuperación de las poblaciones y el aprovechamiento sustentable de su fibra por parte de las comunidades puneñas (Vilá 2012).

Como se ha adelantado, la comprensión de la cosmovisión de las sociedades resulta clave para entender la relación humano-animal, ya que su concepto excede a los grupos no occidentales, abarcando todos los sistemas simbólicos creados por los humanos para comprender el mundo y actuar en él (Cano-Contreras 2009). La cosmovisión andina considera al mundo "como un macroorganismo vivo, donde todo tiene vida y donde todo es necesario para la integridad de la vida de la Pacha” (Van Kessel y Enríquez 2002, 51) y también que “el mundo es un todo vivo, un mundo-animal, que le exige [al hombre andino] respeto y 
cariño” (Van Kessel y Condori 1992, 4). Por su parte, la racionalidad economicista occidental concibe el medio natural como "un gran depósito de recursos materiales disponibles [...] los cuales deben ser explotados considerando la rentabilidad y la ganancia que pueda dar cada recurso" (Van Kessel y Enríquez 2002, 47). Así, animales, plantas y minerales se constituyen como recursos potencialmente aprovechables (Bugallo y Tomasi 2012).

Dentro de la cosmovisión andina, los animales son clasificados como salka o uywa. Salka son los animales de la tierra, propiedad de las deidades que, además, los resguardan y controlan. Uywa son los animales de la gente y, si bien su origen está relacionado con la acción de las deidades, las personas son las encargadas de protegerlos y brindarles bienestar. Así, consideramos que los camélidos, llamas y alpacas son uywa, en tanto que guanacos y vicuñas son salka (Flores Ochoa 1981; Grebe 1984; Vilá 2014, entre otros).

Las fuentes folclóricas y escritas permiten llevar a cabo una aproximación a la forma en que las poblaciones andinas conciben y concibieron a las vicuñas. En las fuentes folclóricas del noroeste argentino se destacan dos figuras míticas vinculadas a las vicuñas: Coquena y Yastay (Vidal de Battini 1984). En los relatos de Salta y Jujuy se hace referencia al Coquena: un hombre pequeño (alternativamente invisible o con forma animal) que se constituye como dueño y protector de los animales de los cerros (especialmente, vicuñas y guanacos). El Coquena protege a las vicuñas de los cazadores arriándolas, escondiéndolas y generando eventos meteorológicos que dificulten su búsqueda. Además, no permite la caza excesiva y sin necesidad ni el uso de armas de fuego. En cambio, sí aprueba la captura mediante el encierro y uso de boleadoras ${ }^{1}$. Una figura similar es el Yastay, también descrito como un hombre pequeño que puede adquirir forma animal. El Yastay (cuyos relatos provienen de Tucumán, Catamarca, La Rioja y San Juan) se encarga de cuidar a los animales silvestres, especialmente guanacos y vicuñas: "cuida que las crías no queden sin madre y que se cace solo lo necesario para que los animales no sean exterminados. Al que caza demasiado lo castiga, lo muerde y puede matarlo” (Bossi 1995, 110). Aunque el Yastay tiene actitudes violentas con los cazadores, también es posible realizar tratos con él para que permita la caza a cambio de ciertos productos (cocho, aguardiente, coca), bajo ciertas condiciones y contemplando potenciales penas. Si bien Coquena y Yastay podrían corresponder a la misma deidad con diferente denominación según el área geográfica de donde proceden las manifestaciones orales, resulta llamativa la identificación del Yastay con el diablo en algunos relatos, razón por la cual se 
resaltan características como su malicia y la posibilidad de generar relaciones contractuales (Costilla 2008-2010; Vidal de Battini 1984).

Las crónicas del periodo de contacto hispano-indígena (Cieza de León [1522-1554] 1996; Cobo [1640-1652] 1956; Garcilaso de la Vega [1609] 1943; Guamán Poma de Ayala [1615] 1993) también otorgan datos para comprender la percepción de las vicuñas. Distintas fuentes concuerdan en que la captura de estos camélidos se encontraba regulada por mecanismos políticos, religiosos y sociales dentro del Imperio inca (Dedenbach-Salazar 1990; Ratto y Orgaz 2008; Vilá 2012; Yacobaccio 2009), dado que las vicuñas eran percibidas como el "ganado de las divinidades" (Dedenbach-Salazar 1990, 192) y denominadas intip llaman, "llamas del Sol" (Guamán Poma de Ayala [1615] 1993). La captura se realizaba mediante su encierro a partir de distintas modalidades, dentro de las que se destacaban el chaku y el lipi (Ratto y Orgaz 2008). Una vez atrapadas con boleadoras y encerradas, se procedía a su esquila: hembras y machos de aspecto fuerte se liberaban para asegurar su multiplicación, mientras que los animales viejos o enfermos se mataban. Estas cacerías las dirigían y realizaban el inca en el Cusco y curacas en las regiones distantes (Dedenbach-Salazar 1990; Ratto y Orgaz 20022004; Yacobaccio 2009).

Después del incario, estas técnicas colectivas de encierro y captura continuaron realizándose. Quiroga (2017) menciona que las poblaciones de los valles Calchaquíes de fines del siglo XIX capturaban vicuñas mediante el chaku, previa ceremonia en la que se pedía a la Pachamama que no las escondiera y se solicitaba la protección del Yastay. Sin embargo, se hace referencia a la matanza para la obtención de carne y cuero y no a la esquila. Boman (1992) relata la cacería comunal en la puna argentino-chilena a comienzos del siglo XX, destacando que la esquila se hacía sobre el cuero de los animales muertos. Si bien las cacerías comunales continuaron luego de la Conquista española y con cierto carácter ceremonial (e.g. ofrendas a deidades andinas), se percibe un cambio en la relación cazador-vicuña: "de su captura, esquila y liberación se pasa a su captura, muerte y extracción de cueros” (Ratto y Orgaz 2008, 116). Esto se revierte hacia mediados del siglo XX, con las políticas de protección de la especie. En zonas de Perú como La Raya y Pampa Galera, se llevan a cabo capturas comunales de vicuñas con esquila y liberación de los animales y ofrendas a la Pachamama (Ratto y Orgaz 2008). Entre las comunidades actuales de la puna de Jujuy, los chaku se combinan con prácticas de ofrenda a la Pachamama para que permita la esquila (Vilá 2014). Si bien ciertos sectores de estas comunidades perciben a las vicuñas como animales pertenecientes a las deidades (Pachamama y Coquena), otros sectores resaltan su potencial económico "como recurso", dada la calidad de su fibra (Wawrzyk y Vilá 2013). 


\section{El caso de estudio: la relación humano-vicuña en el oeste tinogasteño}

El oeste tinogasteño es una amplia región que se localiza en el sudoeste de Catamarca (Argentina) y abarca unos $13.000 \mathrm{~km}^{2}$, incluyendo ambientes contrastantes como el valle de Fiambalá (1.400-2.000 m s. n. m.) y la puna transicional de Chaschuil (3.500-4.500 m s. n. m.) (figura 2). Su ocupación se inició con las primeras sociedades cazadoras recolectoras (ca. 8000 años a. P.). Sin embargo, la mayoría de los estudios se concentraron en las sociedades agropastoriles, desde las primeras ( $c a$. siglo V a. C.) hasta la conquista incaica ( $c a$. siglos XIV y XV) (Ratto 2013).

Con respecto a las sociedades agropastoriles preincaicas ( $c a$. siglos $\mathrm{V}$ a. C. a XIII d. C.), se propuso que los habitantes del valle de Fiambalá se trasladaban temporalmente con sus rebaños hacia la puna transicional de Chaschuil donde cazaban vicuñas (posiblemente de manera individual), evitando así el sacrificio de sus llamas durante sus estadías de pastoreo. La escasa información de fusión ósea brindada por los conjuntos arqueofaunísticos correspondientes a estas sociedades no nos permite sacar conclusiones sobre la existencia de una estrategia de caza dirigida a algún grupo etario (Miyano 2018; Ratto 2017; Ratto, Basile y Feely 2012). En tanto, durante la ocupación incaica las vicuñas continuaron siendo capturadas, aunque bajo la modalidad colectiva del chaku o lipi. Para ello fueron empleadas las macroestructuras La Lampaya y El Matambre, en el área de Cazadero Grande situada a 3.000 m s. n. m. (Ratto y Orgaz 2002-2004). Además, el registro zooarqueológico de San Francisco Inca ( $4.000 \mathrm{~m} \mathrm{s.} \mathrm{n.} \mathrm{m.)} \mathrm{indica} \mathrm{que}$ la matanza de las vicuñas en el sitio fue selectiva, concentrándose en animales adultos (que superaran los tres o cuatro años) (Miyano et al. 2017).

Si bien la relación humano-vicuña tras la Conquista española en el oeste tinogasteño fue abordada previamente por Ratto y Orgaz (2008), consideramos que se puede profundizar su estudio a través del análisis de los relatos de la Colección de Folklore.

La Colección de Folklore (1921) es una recopilación de manifestaciones orales de las distintas comunidades del territorio argentino de principios del siglo XX. Esta obra resultó de un trabajo impulsado por el Consejo Nacional de Educación y realizado por maestros de distintas áreas del país, cuyo objetivo fue recolectar expresiones tradicionales de herencia hispano-indígena, excluyendo elementos de pueblos extranjeros. El trabajo, conocido como Encuesta de Magisterio, reunió en la Colección de Folklore distintos aspectos del saber vernáculo tradicional: creencias y costumbres, narraciones y refranes, arte y 
Figura 2. Mapa del oeste tinogasteño y áreas aledañas

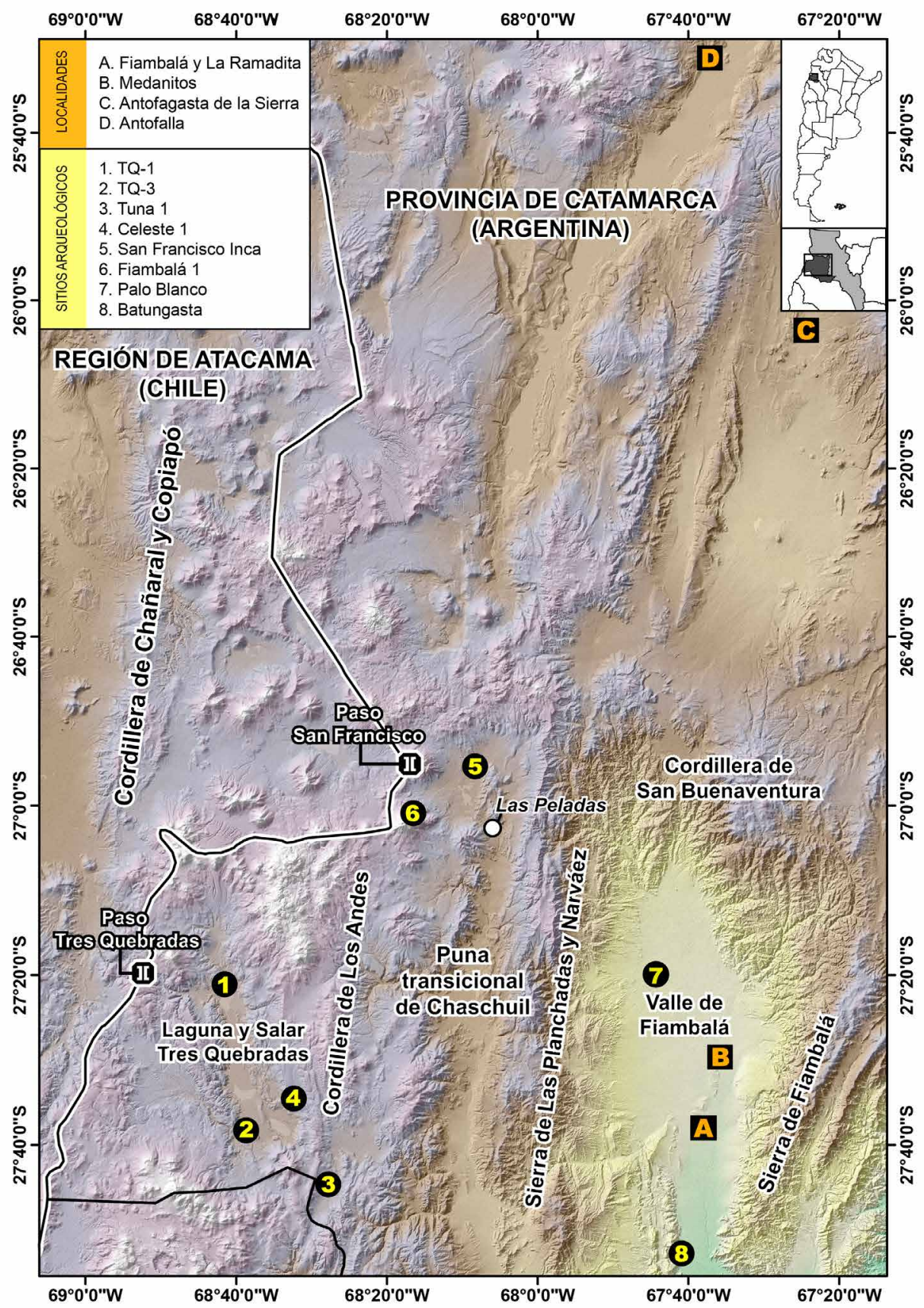

Fuente: mapa elaborado por el Dr. Luis Coll (Carrera del Personal de Apoyo-Instituto de las Culturas) a partir de imágenes satelitales Landsat y DEM de dominio público obtenidas del Servicio Geológico de los Estados Unidos (U. S. Geological Survey). 
conocimientos populares en las diversas ramas de la ciencia (Blache 1992; Crespo y Ondelj 2012; Ferreira 2005).

La colección consta de 88.009 documentos manuscritos agrupados en 3.250 carpetas que corresponden a los registros realizados por cada uno de los maestros (Ferreira 2005). Esta obra se encuentra en el Instituto Nacional de Antropología y Pensamiento Latinoamericano (INAPL). Tras la consulta del catálogo correspondiente, se identificaron 12 carpetas que incluyen manifestaciones orales tradicionales del oeste tinogasteño ${ }^{2}$, concretamente de tres localidades del valle de Fiambalá: La Ramadita, Medanitos y Fiambalá (figura 2). Su lectura se orientó a identificar prácticas, creencias y valoraciones vinculadas a las vicuñas. La información obtenida da cuenta de la percepción de la vicuña a principios del siglo XX y, al menos, durante parte del siglo XIX (considerando que los encuestados relatan experiencias ocurridas en el transcurso de sus vidas). Así, la lectura permitió identificar distintas referencias a las vicuñas:

a. En relación con las supersticiones, se destaca que "el cazador de vicuñas o guanacos guarda siempre colgado cerca del fogón la mandíbula inferior de todas las piezas que caza como un medio de que no le abandone la suerte para cazar" (carpeta 93, La Ramadita, Escuela Infantil n. $\left.{ }^{0} 114\right)^{3}$.

b. Un relato da cuenta del uso de piedras bezoares de camélidos silvestres para tratar malestares físicos: "para curar del aire a los niños acostumbra la gente del pueblo disolver piedra vesal (concreción formada en el estómago del guanaco o vicuña) en agua y hacer beber al enfermo, sahumándolo con 'pichana”' (carpeta 281, Fiambalá, Escuela Nacional n. $\left.{ }^{0} 24\right)^{4}$.

c. Otro relato sostiene que para los habitantes de los cerros el hecho de observar a las vicuñas bajar con precipitación de las cumbres es "anuncio de borrascas y tempestades en la cordillera" (carpeta 281, Fiambalá, Escuela Nacional n. $\left.{ }^{\circ} 24\right)^{5}$.

2 La digitalización de las 12 carpetas fue realizada por la Dra. Ratto entre septiembre y octubre del 2016 gracias a un permiso para fotografiar los microfilms otorgado por la Dra. Rolandi, directora del INAPL en esos momentos.

4 Registrado por E. Ruchelli y narrado por J. Carrizo (80 años).

5 Registrado por E. Ruchelli y narrado por C. de Azbar (50 años). 
d. Se destacan cuatro relatos referidos al Yastay y su relación con los cazadores de vicuñas y guanacos ${ }^{6}$. El Yastay es denominado como "dueño de las vicuñas”, así como también de los guanacos, y en uno de los relatos se lo vincula con la Pachamama quien es mencionada como su mujer. Su aspecto es humano, aunque puede adquirir forma animal (vicuña, guanaco o perro). Vive en las montañas y se les presenta a los cazadores de vicuñas y guanacos de manera hostil y advirtiéndoles que él es dueño de los animales y que para cazarlos deben obsequiarle distintos productos, entre los que se destacan la harina de chaclión', cintas de colores, maíz tostado, flores de lana teñida y burros. El Yastay les advierte que no deben cazar vicuñas hembras ni sus crías y que, solo cuando necesiten carne o cuero, él podría permitirles la caza de machos a cambio de harina de chaclión, su comida favorita ${ }^{8}$. El hecho de no cumplir con la entrega de las ofrendas o revelar la relación establecida con el Yastay a otras personas podía llevar a la muerte del cazador.

e. Finalmente, las vicuñas también adquieren voz y forman parte de la siguiente fábula:

Una vicuña y su cría se fueron a pacer en un campo, de pronto la vicuñita vio unos perros y le gritó a la madre: juay, mamita, los zarcos ${ }^{9}$ vienen por la quebrada, por la cañada, las patas golpiando, la sangre chorriando.

La vicuña le contestó: mentís hijita, que son las flores de cardón.

Pero no tardó en ver que era verdad y a su vez gritó a la vicuñita: dispara hijita, menea las uñas, sube el filito; vamos a los pastos secos que vate [sic] el viento de Pío Pascual. (Carpeta 91, La Ramadita, Escuela Infantil n. $\left.{ }^{0} 114\right)^{10}$

6 Los relatos se incluyen en las siguientes carpetas: a) 296 (Fiambalá, Escuela Nacional n. 24), registrado por F. Serrano y narrado por E. Serrano (65 años); b) 91 (La Ramadita, Escuela Infantil n..$^{1140)}$, registrado por C. Centa y narrado por M. Alegre (60 años); c) 93 (La Ramadita, Escuela Infantil n. ${ }^{\circ}$ 114), registrado por E. Cerda; y d) 19 (Fiambalá, Escuela Nacional n..$^{\circ}$ 24), registrado por D. Almendra. En los últimos dos casos no se determina el narrador dado que las maestras sostienen que se trata de una creencia popular. Chaclión es una de las denominaciones del amaranto. zador podía capturar "decenas de decenas de guanacos", de modo tal que la caza solo por necesidad en este caso particular no se percibe. 


\section{Discusión}

El análisis de las doce carpetas permitió la identificación de distintas referencias a las vicuñas. A continuación, se discuten y contextualizan dichas referencias con datos de carácter histórico, arqueológico, folclórico y antropológico siguiendo los tres ejes propuestos al inicio del trabajo: a) la captura de vicuñas, b) su valor tangible y c) su valor intangible.

\section{La captura de vicuñas}

Si se considera la distribución de las vicuñas (puna, ca. 3.500-4.800 m s. n. m.) y que los relatos de la Colección de Folklore analizados provienen de habitantes del valle de Fiambalá (1.400-2.000 m s. n. m.), su cacería supuso el traslado de los cazadores desde el ambiente valliserrano hacia el puneño, que equivale a una distancia aproximada de $100 \mathrm{~km}$ a través de los conectores naturales que unen ambos ambientes. Estas travesías tendrían una duración de entre siete y diez días, considerando la información suministrada por pobladores locales a la segunda autora, que es compatible con la información brindada por Núñez (2011) (figura 2). Diversos relatos de la Colección de Folklore hacen referencia a "los cerros” como el hábitat de estos camélidos a los que se trasladan los cazadores del valle para capturarlos ${ }^{11}$. La interacción valle-puna ha sido documentada en el oeste tinogasteño tanto durante momentos prehispánicos (Ratto 2013; Ratto, Basile y Feely 2012) como posteriores a la Conquista española (Molina 2010). Particularmente, se destaca la conexión entre el valle de Fiambalá y la puna transicional de Chaschuil mediante distintos conectores naturales presentes en las sierras de Las Planchadas y de Narváez (figura 2) por parte de las sociedades agropastoriles prehispánicas (Ratto 2013). Con respecto a esto cabe recordar la presencia de restos de Vicugna vicugna en ciertos contextos de la localidad arqueológica de Palo Blanco (siglos IV a X) y en el sitio inca Batungasta (siglos XV y XVI), ambos emplazados en el valle de Fiambalá a 1.900 y $1.480 \mathrm{~m}$ s. n. m. respectivamente (Miyano 2018, 2019) (figura 2). Por su parte, Molina (2010) destaca que, entre los siglos XVII y XX, distintos caminos conectaron el valle de Fiambalá con localidades de la puna sur (Antofagasta de la Sierra y Antofalla), cruzando la cordillera de San Buenaventura, y con áreas transandinas (Chañaral y Copiapó), a

\footnotetext{
11 En los relatos se percibe una diferenciación entre los habitantes de las localidades del valle de Fiambalá y los de "los cerros", quienes viven allí de manera permanente y son denominados por los primeros como collas.
} 
través de los pasos San Francisco y Tres Quebradas que eran usados con fines comerciales y de intercambio (figura 2). En relación con esto, sostiene que "la caza de vicuñas y guanacos fue un estupendo aliciente para recorrer los diversos lugares y asentamientos de la puna y el desierto de Atacama” (115). Además, propone la existencia de una red territorial transcordillerana sustentada en lazos de parentesco, amistad y compadrazgo y sostenida por la movilidad y los intercambios durante momentos coloniales y republicanos (Molina 2010). En la Colección de Folklore se mencionan distintos pasos utilizados por los habitantes del valle de Fiambalá tanto hacia Chile como hacia Bolivia ${ }^{12}$, los cuales coinciden con los descritos por Molina (2010). Así, el traslado de personas desde el valle de Fiambalá hacia la puna para la caza de vicuñas posiblemente se constituya como una práctica de profundo arraigo temporal, enmarcada en un contexto general y persistente de circulación de personas, animales, recursos e ideas. Sin embargo, las razones que llevaron a las personas a trasladarse hacia las tierras altas para la captura de vicuñas no deben haber sido las mismas a lo largo del tiempo, pudiendo responder a la subsistencia o a la obtención de recursos para producción, intercambio o comercialización.

La información arqueológica someramente mencionada por Valero-Garcés y Ratto (2005) y otra recientemente registrada en un estudio de impacto arqueológico (Ratto 2017) adquieren relevancia en el contexto regional cuando relacionamos la materialidad de esos ambientes cordilleranos con la historia documental y oral desarrollada en este trabajo. La articulación de distintos tipos de datos sugiere que las rutas mencionadas en las fuentes tienen una historia mucho más profunda, relacionada con el movimiento de grupos con fines de caza de camélidos o extracción de sal, además de conectar una y otra vertiente de la cordillera de los Andes. Sitios arqueológicos como Celeste 1, Tuna 1, TQ-1 y TQ-3 (figura 2) dan cuenta de ello:

a. Celeste 1 (4.526 m s. n. m.) se localiza a la vera de la laguna Celeste, en el área de Tres Quebradas. Se trata de un conjunto de más de 20 estructuras (muro simple, pirca seca) de forma circular o subcircular, aisladas o asociadas en conjuntos de dos, interconectados mediante un muro bajo. La disposición de las estructuras permite proponer como

12 Los pasos mencionados en las carpetas 93 y 166 son San Francisco, Los Patos, Tres Quebradas, Barrancas Blancas y Potrero Grande hacia Chile y Socaire, Socompa y del Desierto hacia Bolivia. Hasta 1899 los límites entre Chile, Argentina y Bolivia no eran los actuales; durante gran parte del siglo XIX el área de Antofagasta de la Sierra y la cordillera de San Buenaventura se constituyó como la frontera boliviana-argentina (Molina 2010), de modo que el valle de Fiambalá se encontraba en una región de triple frontera. 
hipótesis que se trata de paraderos de caza prehispánicos o lugares de parada-campamento de grupos caravaneros.

b. Tuna 1 (4.310 m s. n. m.) se emplaza a la vera de la laguna Tuna, en el área de la ruta a la cordillera de los Andes por Las Coipas. Se trata de tres recintos de piedra en mal estado de conservación debido a procesos de reclamación. Entre los artefactos se destacan puntas líticas de basalto pedunculadas con hombro, correspondientes a diseños de las sociedades del primer milenio de la era de la región. Dichas puntas se encuentran asociadas con un conjunto cerámico que, por sus características tecno-morfo-decorativas, remiten a los mismos momentos. El sitio y las rocas de los muros fueron reclamados para la construcción de una calzada de acceso a la laguna Tuna, posiblemente vinculada con la explotación de sal en el pasado.

c. TQ-1 (4.105 m s. n. m.) y TQ-3 (4.179 m s. n. m.) se ubican en el sector norte y sur, respectivamente, del área del salar y las lagunas de Tres Quebradas. TQ-1 se trata de tres parapetos (muro simple, pirca seca) de forma subcircular, con abundantes desechos líticos, puntas, preformas y nódulos de obsidiana. El sitio se interpretó como un lugar de vigilancia de camélidos silvestres con realización de talla en tiempo de espera. TQ-3 se trata de 15 estructuras (muro simple, pirca seca) asociadas con un abundante conjunto lítico de desechos. Entre los escasos artefactos formatizados se destaca una punta pedunculada de aletas entrantes. TQ-3 también se vincularía con actividades de caza de camélidos en las tierras altas. Desafortunadamente, el material óseo recuperado fue escaso, no diagnóstico y con mala preservación. Los dos fechados radiométricos de TQ-3 ubican el uso de los espacios cordilleranos a fines del siglo XI (Ratto 2017) ${ }^{13}$.

En suma, la oralidad informa sobre el uso de los espacios puneños y cordilleranos con fines de caza de camélidos por parte de los habitantes del valle de Fiambalá en los siglos XIX y XX. La articulación de esa información folclórica con datos históricos y arqueológicos indica que la movilidad valle-puna y el uso de este último ambiente para la captura de vicuñas presentan una profundidad temporal mayor, que se extiende, al menos, hasta el primer milenio de la era. 


\section{El valor tangible de las vicuñas}

Los habitantes del oeste tinogasteño del siglo XIX y principios del siglo XX les otorgaron un valor tangible a las vicuñas. En los relatos se destaca que su captura se realizaba para aprovechar la carne (valor nutricional), el cuero (valor tecnológico) y las piedras bezoares (valor medicinal). Los datos arqueológicos e históricos de la región nos permiten evaluar el valor tangible de la vicuña diacrónicamente. Con respecto a la carne, su consumo se encuentra documentado en el oeste tinogasteño desde momentos de las primeras sociedades agropastoriles hasta las incaicas, considerando la identificación de marcas de descarne en los restos óseos (Miyano 2018, 2019; Miyano et al. 2017). Sobre los cueros, Molina (2010) destaca que en tiempos históricos y hasta 1970 eran trasladados desde la puna de Atacama a los valles aledaños para comercializarlos, siendo el valle de Fiambalá un locus de manufactura de textiles a partir del hilado y tejido de la fibra de vicuña. La práctica del chaku realizada en la puna transicional de Chaschuil durante la ocupación incaica permite especular acerca de la esquila de este camélido y el uso de su fibra (Miyano et al. 2017; Ratto y Orgaz 2008) ${ }^{14}$. Así, y si bien el recurso que se aprovecha es el mismo (fibra), estaríamos ante la presencia de un cambio en la valorización de la vicuña producto de la Conquista española, y se resalta fundamentalmente su condición de "recurso" durante momentos históricos (Ratto y Orgaz 2008; Van Kessel y Enríquez 2002). Finalmente, y en lo relativo a las piedras bezoares, aunque no hay antecedentes locales de su aprovechamiento, estos elementos fueron (y son) valorados por las poblaciones andinas que les han otorgado usos medicinales y rituales (Míguez et al. 2017).

En síntesis, la carne, el cuero, la fibra y las piedras bezoares fueron recursos utilizados durante los siglos XIX y XX y, posiblemente, durante el pasado prehispánico por las poblaciones agropastoriles. Sin embargo, y considerando la amplia escala temporal, la Conquista española y el periodo republicano como procesos disruptivos en los modos de vida locales, es posible que el aprovechamiento de las vicuñas se haya enmarcado en distintas cosmovisiones.

En el sitio inca Batungasta (1.480 m s. n. m.) se detectaron cordeles de fibra animal indeterminada. En cuanto a las primeras sociedades agropastoriles, en el Recinto 1 del sitio Fiambalá 1 (5.000 m s. n. m.), ubicado temporalmente en el siglo VIII, se registraron cueros y vellones que, considerando la presencia exclusiva de vicuñas en el registro zooarqueológico asociado, podrían pertenecer a dicha especie (Ratto y De Nigris 2012) (figura 2). 


\section{El valor intangible de las vicuñas}

Las manifestaciones orales tradicionales también son una vía de acceso a los valores intangibles otorgados a las vicuñas por parte de los pobladores del oeste tinogasteño del pasado reciente. En las carpetas analizadas se identificaron diversas referencias a las vicuñas que se asocian al Yastay. Según los relatos, este se les presenta a los cazadores advirtiéndoles que él es el dueño y protector de vicuñas o guanacos, y que deben pedirle permiso para poder capturarlos. Además, en uno de ellos se lo vincula a la Pachamama, quien aparece como su mujer. La descripción del Yastay coincide con las registradas por Vidal de Battini (1984) en Catamarca, Tucumán, La Rioja y San Juan. En los relatos analizados se encuentra implícita la percepción andina de las vicuñas en tanto salka, es decir, animales de la tierra que no son de los humanos sino de las deidades que los protegen y controlan y con las que se debe negociar su captura (Flores Ochoa 1981; Grebe 1984; Vilá 2014). El consentimiento del Yastay para que los cazadores puedan capturarlas está sujeto a distintas condiciones. Una de ellas es la realización de ofrendas, entre las que se destacan elementos de origen andino (harina de chaclión y maíz) y del Viejo Mundo (burros). Más allá de esta variabilidad en los tipos de ofrendas, lo fundamental es que el "pago" necesariamente debe realizarse. Esta conducta fue reportada en las comunidades actuales de la puna de Jujuy —ofrendas a la Pachamama previas a la esquila de las vicuñas-(Vilá 2014) y en las de los valles Calchaquíes de fines del siglo XIX — ofrendas a la Pachamama y al Yastay previas a la realización de las cacerías-(Quiroga 2017).

Otra condición establecida por el Yastay es que se debe cazar solo por necesidad y evitar el sacrificio de hembras y crías. Pese a que se cumpla con el "pago", la caza no es libre sino que se encuentra restringida y la matanza es selectiva. Las crónicas del periodo de contacto hispano-indígena dan cuenta de la selectividad de la caza: los animales sacrificados eran los viejos o enfermos (Dedenbach-Salazar 1990; Ratto y Orgaz 2002-2004). Así, resulta interesante recordar que en el oeste tinogasteño existe evidencia de la cacería de vicuñas durante la ocupación incaica (Ratto y Orgaz 2002-2004) y que el registro zooarqueológico se conforma principalmente por individuos adultos (Miyano et al. 2017). Hasta el momento, el registro zooarqueológico de las sociedades preincaicas no nos permite ahondar en los perfiles etarios de estos camélidos y, por lo tanto, en la posibilidad de proponer una caza dirigida. Así, es posible que en el oeste tinogasteño haya habido una continuidad en los modos en que las comunidades locales percibían a las vicuñas y que esto limitara su caza a determinados individuos desde, al menos, la ocupación incaica hasta principios del siglo XX. Sin embargo, resulta difícil 
saber: a) qué aspectos simbólico-ideológicos eran los que concretamente regían la restricción durante los momentos incaicos (más allá de la concepción salka de las vicuñas); y b) si la restricción durante el periodo posterior a la Conquista española era considerada por toda la población del oeste tinogasteño o solo por un sector.

Otros rasgos del Yastay son su actitud virulenta y la predisposición a entablar relaciones contractuales que permitan cazar más de lo necesario. Costilla (2008-2010) sostiene que el Yastay es un personaje andino resignificado a partir del cristianismo y relacionado con el diablo. Sin embargo, afirma que, "aunque esto le confiera un carácter más nefasto y siniestro, es posible que desde la propia cosmovisión local el Yastay haya sido concebido siempre como un ser temible y peligroso" (62). Así, por un lado, se le otorga profundidad temporal al mito; y, por otro, se lo muestra permeable a resignificaciones a partir de elementos de una religión ingresada tras la Conquista española, aunque conservando un núcleo y mensaje esencialmente andinos. Si bien en el caso de los relatos analizados de la Colección de Folklore no se detecta el vínculo Yastay-diablo, sí se destacan su malicia y la posibilidad de hacer un trato (características propias del diablo). Además, en dos de los tres relatos recopilados en Fiambalá por Vidal de Battini (1984) se nombra explícitamente al Yastay como el diablo.

En cuanto a la distribución del mito, Molina (2010) sostiene que entre los habitantes de la cordillera de Copiapó (Chile) se relatan historias del Yastay. Esto último se constituye como otra evidencia a favor de la circulación no solo de personas sino también de ideas entre ambos lados de la cordillera de los Andes, tal como se ha desarrollado en el acápite anterior.

El mito del Yastay se constituye como parte de los sistemas simbólicos que conforman la cosmovisión andina de los pobladores del oeste tinogasteño durante el siglo XIX y principios de siglo XX. Este mito tiene un carácter instrumental dado que guía la concepción y la acción humana sobre las vicuñas. Establece y propone pautas de conductas adecuadas (realizar ofrendas, cazar solo por necesidad, evitar la matanza de hembras y crías), así como también proyecta conductas impropias (no realizar ofrendas, cazar masivamente, sacrificar hembras y crías) que tienen como correlato un castigo.

Sin embargo, y pese a la circulación del mito del Yastay en el oeste tinogasteño, es posible que cierto sector de la sociedad lo haya ignorado y, por lo tanto, no haya tenido efecto en sus conductas relacionadas con la captura y el uso de las vicuñas. Cabe recordar que las poblaciones de vicuñas se redujeron notoriamente durante los momentos posteriores a la Conquista española, producto de la caza indiscriminada (Vilá 2012; Yacobaccio 2009). Este proceso culminó con 
el desarrollo y puesta en práctica de legislaciones provinciales y nacionales de conservación y protección de estos camélidos silvestres (Vilá 2012). Aquellos que desarrollaron prácticas de caza que llevaron a una reducción crítica de las poblaciones de vicuñas no lo deben haber hecho permeados por los sistemas simbólicos de la cosmovisión andina, sino por la racionalidad economicista occidental en la que los animales son percibidos como recursos susceptibles de explotación. Resulta relevante discutir la fábula transcrita en la que una vicuña y su hija se escapan de humanos que son vistos como una amenaza. Este relato, de aparente gran difusión en el noroeste argentino (Tebes y Karlovich 2010), posiblemente sea una forma de dar cuenta de la matanza masiva de estos camélidos desde la óptica de los animales. Los humanos representados en la fábula son zarcos, es decir, personas de ojos claros. Respecto a esto, Tebes y Karlovich (2010) sostienen que la narración funcionaría también como una alegoría a la Conquista de los españoles. Así, las manifestaciones orales tradicionales se constituyen no solo como una vía de acceso a la cosmovisión de los grupos humanos y su percepción, valoración y uso de los animales, sino también como un campo que puede encriptar eventos y procesos de carácter histórico, en este caso la Conquista española o la matanza indiscriminada de vicuñas.

Por último, resulta interesante señalar que el valle de Fiambalá fue despoblado, producto de las encomiendas del siglo XVII (Ratto y Boixadós 2012) y repoblado hacia fines del siglo XVIII con criollos (Ratto 2013). La ocupación de las tierras altas (sierra de Narváez y cordillera de San Buenaventura) no parece haber sido similar. En los relatos registrados se afirma que "los habitantes de la parte montañosa del departamento son en su mayor parte aborígenes con muy poca cruza europea” (carpeta 93, La Ramadita, Escuela Infantil n. ${ }^{\circ} 114$ ), y se los denomina como "collas habitantes de los cerros de vida netamente ganadera" y "pueblos incultos que viven en las estancias (serranías donde crían sus ganados)" (carpeta 281, Fiambalá, Escuela Nacional n. ${ }^{\circ}$ 24). Así, el escenario demográfico de fines del siglo XIX y principios del XX fue un complejo entramado cultural en el que existieron diversas identidades con cosmovisiones no compartidas, por lo tanto, albergó percepciones y valoraciones disímiles en torno a las vicuñas.

De lo anterior se desprende que, si bien la relación humano-vicuña mediada por el Yastay en los siglos XIX y XX no debe ser extendida a todos los habitantes del oeste tinogasteño, la presencia del mito en la Colección de Folklore indica que su conocimiento en la región fue amplio. Además, cabe recordar que durante la dominación incaica de la región es posible que haya existido una restricción en la caza de estos animales, aunque resulta difícil determinar las características de la figura mítica (si la hubo) que haya normado la matanza de las vicuñas. Así, 
y a pesar de la caza masiva durante el periodo colonial y gran parte del republicano, la circulación de este mito del dueño de los animales a principios del siglo $\mathrm{XX}$ sugiere que se constituyó como un vector de la relación humano-vicuña a lo largo del tiempo, con raíces en el pasado prehispánico y evidente vinculación con la cosmovisión andina.

\section{Conclusiones}

El análisis de las manifestaciones orales tradicionales de la Colección de Folklore provenientes del oeste tinogasteño permitió abordar la relación humano-vicuña en dicho espacio durante el pasado reciente. Asimismo, la articulación con datos de carácter histórico, arqueológico y zooarqueológico posibilitó evaluar esa relación diacrónicamente, cubriendo así una escala temporal amplia (desde los inicios del primer milenio de la era hasta principios del siglo XX) y, de ese modo, enriqueciendo el análisis etnozoológico.

La discusión de distintos tipos de datos permitió la evaluación de la hipótesis planteada al inicio del trabajo. Por un lado, y considerando la primera parte de la hipótesis, se concluye que, durante el pasado reciente del oeste tinogasteño (siglos XIX y XX), la percepción y valoración humana de la vicuña se encontró parcialmente enmarcada en los sistemas simbólicos que estructuran la cosmovisión andina. Sostenemos esto dado que fue posible detectar en los relatos analizados ciertos elementos simbólicos estrechamente vinculados con la forma de comprender y actuar en el mundo correspondiente a la cosmovisión andina. Entre ellos, se destacan la idea implícita de las vicuñas como salka (animales de la tierra) y el mito del Yastay, dueño de los animales, que regula la caza (Costilla 2008-2010; Flores Ochoa 1981; Grebe 1984; Vidal de Battini 1984; Vilá 2014). La presencia tácita del concepto salka y explícita del Yastay permite proponer que al menos parte de la sociedad del pasado reciente del oeste tinogasteño enmarcaba la percepción de las vicuñas (y su consecuente forma de actuar y valorarlas) dentro de la cosmovisión andina. No obstante, dicha percepción no debe generalizarse a toda la población de la región, más aún considerando el complejo proceso de despoblamiento y repoblamiento del oeste tinogasteño luego de la Conquista española (Ratto y Boixadós 2012), que resultó en una demografía compleja, con habitantes de orígenes e identidades diversas (Ratto 2013). La reducción masiva de la población de vicuñas como producto de la caza indiscriminada permite proponer que en el pasado reciente del oeste tinogasteño también operaron otras 
cosmovisiones distintas a la andina, que prohibía estrictamente la matanza ilimitada. Así, la cosmovisión andina convivió con la racionalidad economicista occidental, que considera a los animales recursos potencialmente explotables y generadores de ganancia. Lejos de ser reduccionistas y considerar a estas cosmovisiones dicotómicas e incompatibles, creemos que pudieron coexistir y convivir dentro de una misma población, tal y como ha sido demostrado en estudios actuales en comunidades de la puna jujeña (Vilá 2014; Wawrzyk y Vilá 2013).

Por otro lado, y considerando la segunda parte de la hipótesis, se concluye que el uso y aprovechamiento de las vicuñas en el pasado reciente respondió a modalidades llevadas a cabo durante los momentos prehispánicos y muestra ciertas continuidades a lo largo del tiempo. Así, se destaca la profundidad temporal de la captura de vicuñas (sea cual fuera la técnica empleada) y de la organización social de las cacerías que implicaban el traslado de los cazadores desde el valle de Fiambalá hasta la puna transicional de Chaschuil y el posterior retorno. A su vez, se remarca que carne, cueros, fibra y, posiblemente, piedras bezoares han sido los recursos aprovechados de este animal a lo largo de las centurias.

A modo de agenda a futuro, se considera que es necesario completar el estudio etnozoológico de cuenta larga con estudios sistemáticos de la relación humano-vicuña en el presente. Se sabe de dos situaciones que se adelantan aquí y que merecen ser profundizadas en un próximo estudio. Por un lado, en los últimos 25 años se han reportado casos de caza furtiva, fundamentalmente para obtener cueros. Así, es posible sostener la presencia en la actualidad de la percepción de la vicuña como "recurso". Por otro lado, se han registrado dos casos en los que crías de vicuñas fueron capturadas por habitantes de las tierras altas y mantenidas en cautiverio ${ }^{15}$, incorporándolas como animales de compañía e, incluso, poniéndoles nombre. Un caso se documentó en octubre del 2003 en el puesto de Las Copias (3.700 m s. n. m.), emplazado en el corredor que permite el acceso al área cordillerana de Tres Quebradas. El otro caso se registró en febrero del 2005 en el puesto de Vialidad Provincial de Las Grutas (4.000 m s. n. m.). Allí, una vicuña macho fue nombrada Pacotillo, alimentada a mamadera y criada por empleados viales. Este fenómeno de “mascotización” resulta interesante para ser incorporado en estudios etnozoológicos venideros.

15 En tiempos del incario algunas crías de vicuñas eran mantenidas en cautiverio como actividad complementaria al chaku, posiblemente con fines de selección artificial (Ratto y Orgaz 2008). Esta práctica es usada por pastores de Antofagasta de la Sierra que cruzan vicuñas machos con llamas para mejorar la fibra de las crías. 


\section{Referencias}

Blache, Martha. 1992. "Folklore y nacionalismo en la Argentina: su vinculación de origen y su desvinculación actual”. Runa 20 (1): 69-89. https://doi.org/10.34096/runa.v20i1.2313

Boman, Eric. 1992. Antigüedades de la región andina de la República Argentina y del desierto de Atacama, t. II. San Salvador de Jujuy: Universidad Nacional de Jujuy.

Bossi, Elena. 1995. “Seres mágicos de la Argentina”. Escritos, Revista del Centro de Ciencias del Lenguaje 11-12: 87-111. http://cmas.siu.buap.mx/portal_pprd/work/sites/escritos/resources/LocalContent/38/1/87-111.pdf

Bugallo, Lucila y Jorge Tomasi. 2012. "Crianzas mutuas. El trato a los animales desde las concepciones de los pastores puneños (Jujuy, Argentina)”. Revista Española de Antropología Americana 42 (1): 205-224. https://doi.org/10.5209/rev_REAA.2012.v42.n1.38644

Cano-Contreras, Eréndira. 2009. "El papel de la cosmovisión en el conocimiento etnozoológico”. En Costa, Vargas y Santos 2009, 54-66.

Cieza de León, Pedro. (1522-1554) 1996. Crónica del Perú. Segunda parte. Lima: Pontificia Universidad Católica del Perú.

Cobo, Bernabé. (1640-1652) 1956. Historia del Nuevo Mundo. Madrid: Biblioteca de Autores Españoles.

Cortázar, Augusto. 1959. Esquema del folklore. Conceptos y métodos. Buenos Aires: Columba.

Costa Neto, Eraldo, Mauricio Vargas Clavijo y Dídac Santos Fita. 2009a. Introducción a Costa, Vargas y Santos 2009, 15-20.

—, coords. 2009b. Manual de etnozoología. Una guía teórico-práctica para investigar la interconexión del ser humano con los animales. Valencia: Tundra Ediciones.

Costilla, Julia. 2008-2010. "Cristianismo indígena en el NOA: resignificaciones y resimbolizaciones en relatos orales del siglo XX (1940-1998)". Cuadernos del Instituto Nacional de Antropología y Pensamiento Latinoamericano 22: 59-70.

Crespo, Carolina y Margarita Ondelj. 2012. "Patrimonio y folklore en la política cultural en Argentina (1943-1964)”. Avá 21: 129-150. http://argos.fhycs.unam.edu.ar/hand le/123456789/592

Dedenbach-Salazar Sáenz, Sabine. 1990. Inka Pachaq LlamanpaWillaynin. Uso y crianza de los camélidos en la época incaica. Estudio lingüístico y etnohistórico basado en las fuentes lexicográficas y textuales del primer siglo después de la Conquista. Bonn: Bonner Amerikanistische Studien.

Ferreira, Leticia. 2005. "Proyecto de microfilmación de la Colección de Folklore de 1921". En Seminario Dilemas de la Biblioteca Actual. La Creatividad frente a la Crisis, compilado por Alberto Morán, Beatriz Bozzini y Elsa Solimano, 109-120. Buenos Aires: INAP.

Flores Ochoa, Jorge. 1981. "Clasificación y nominación de camélidos sudamericanos”. En La tecnología en el mundo andino, editado por Heather Letchtman y Ana Soldi, 195-232. Ciudad de México: Universidad Autónoma de México. 
Franklin, William. 1982. "Biology, Ecology, and Relationship to Man of the South American Camelids”. En Mammalian Biology in South America, editado por Michael Mares y Hugh Genoways, 547-489. Pittsburgh: University of Pittsburgh.

Garcilaso de la Vega, Inca. (1609) 1943. Comentarios reales de los incas. Buenos Aires: Emecé.

Grebe, María. 1984. "Etnozoología andina: concepciones e interacciones del hombre andino con la fauna altiplánica”. Estudios Atacameños 7: 335-347. 10.22199/S07181043.1984. 0007.00032

Guamán Poma de Ayala, Felipe. (1615) 1993. Nueva crónica y buen gobierno. Ciudad de México: Fondo de Cultura Económica.

Izeta, Andrés. 2008. "Late Holocene Camelid Use Tendencies in Two Different Ecological Zones of Northwestern Argentina”. Quaternary International 180: 135-144. https://doi. org/10.1016/j.quaint.2007.08.026

Mengoni Goñalons, Guillermo. 2008. "Camelids in Ancient Andean Societies: A Review of the Zooarchaeological Evidence”. Quaternary International 185: 59-68. https://doi. org/10.1016/j.quaint.2007.05.022

Míguez, Gabriel, Norma Nasif, María Videsm, Mario Caria y Mónica Gudemos. 2017. "Piedras bezoares en contexto: primer estudio de su relevancia en comunidades prehispánicas del noroeste de Argentina”. Chungara 49 (3): 343-357. http://dx.doi.org/10.4067/ S0717-73562017005000019

Miyano, Juan Pablo. 2018. "El uso de animales por las sociedades agropastoriles tempranas: análisis zooarqueológico de un basural de la aldea de Palo Blanco (valle de Fiambalá, Catamarca)”. Arqueología 24 (1): 77-101. https://doi.org/10.34096/arqueologia.t24.n1.4227

—. 2019. "Humanos y animales en el oeste tinogasteño (Catamarca, Argentina): su relación a lo largo del tiempo desde el siglo IV a. C. hasta la actualidad”. Tesis doctoral, Facultad de Filosofía y Letras, Universidad de Buenos Aires, Buenos Aires.

Miyano, Juan Pablo, Irene Lantos, Norma Ratto y Martín Orgaz. 2017. “Animales e incas en el oeste tinogasteño (Catamarca, Argentina)”. Latin American Antiquity 28 (1): 28-45. https://doi.org/10.1017/laq.2016.7

Molina, Raúl. 2010. "Collas y atacameños en el desierto y la puna de Atacama y el valle de Fiambalá: sus relaciones transfronterizas”. Tesis doctoral, Instituto de Investigaciones Arqueológicas, Universidad Católica del Norte; Departamento de Antropología, Universidad de Tarapacá, Arica.

Núñez Srýtr, Marinka. 2011. "Rutas, viajes y convidos; territorialidad peineña en las cuencas de Atacama y Punta Negra”. En En ruta: arqueología, historia y etnografía del tráfico surandino, editado por Lautaro Núñez y Axel Nielsen, 373-398. Córdoba: Brujas. https://www. academia.edu/7632461/En_Ruta_Arqueolog\%C3\%ADa_Historia_y_Etnograf\%C3\%ADa_ del_Tr\%C3\%A1fico_Sur_Andino

Olivera, Daniel. 2001. "Sociedades agropastoriles tempranas: el Formativo Inferior del Noroeste Argentino”. En Historia argentina prehispánica I, editado por Eduardo Berberián y Axel Nielsen, 83-126. Córdoba: Brujas. 
Olivera, Daniel y Jennifer Grant. 2009. "Puestos de altura en la puna argentina: zooarqueología de Real Grande 1 y 6 y Alero Tomayoc”. Revista del Museo de Antropología 2 (1): 151-168. https://doi.org/10.31048/1852.4826.v2.n1.5415

Quiroga, Adán. 2017. Folklore calchaquí. Buenos Aires: Fundación de Historia Natural Félix de Azara.

Ratto, Norma. 2013. Delineando prácticas de la gente del pasado. Los procesos socio-históricos del oeste tinogasteño (Catamarca). Buenos Aires: Publicaciones de la Sociedad Argentina de Antropología. https://doi.org/10.5354/0719-1472.2013.26554

—. 2017. "Informe estudio de impacto arqueológico proyecto Tres Quebradas (dpto. Tinogasta, Catamarca)”. Presentado a la Dirección de Antropología de Catamarca. Manuscrito.

Ratto, Norma, Mara Basile y Anabel Feely. 2012. "Rutas y espacios conectados: las tierras altas y bajas del oeste tinogasteño ca. 2000-1000 a. P. (Catamarca)”. Revista Chilena de Antropología 26: 33-58. DOI: 10.5354/0719-1472.2013.26554

Ratto, Norma y Roxana Boixadós. 2012. "Arqueología y etnohistoria. La construcción de un problema de investigación (Abaucán, Tinogasta, Catamarca)”. Memoria Americana 20 (2): 187-220.

Ratto, Norma y Mariana de Nigris. 2012. "El consumo de camélidos (Vicugna vicugna) en un sitio ceremonial de la alta cordillera andina (departamento Tinogasta, Catamarca, Argentina)”. Chungara 44 (2): 287-298. http://dx.doi.org/10.4067/S0717-73562012000200006

Ratto, Norma y Martín Orgaz. 2002-2004. "La cacería en los Andes: registro material del chaku en la puna meridional catamarqueña (Cazadero Grande, Tinogasta)". Arqueología 12: 72-102. http://proyectopacha.com.ar/ratto-n-y-m-orgaz-2002-2004-la-caceria-en-los-andesregistro-material-del-chaku-en-la-puna-meridional-catamarquena-cazadero-grande-dp to- tinogasta-catamarca-arqueologia-1272-102/

-. 2008. "Transformaciones sociales de la cacería comunal de vicuñas desde los inkas hasta las comunidades andinas actuales”. En Zooarqueología hoy. Encuentros hispano-argentinos, editado por Juan Díez, 109-123. Burgos: Universidad de Burgos.

Santos Fita, Dídac, Eraldo Costa Neto y Eréndira Cano-Contreras. 2009. "El quehacer de la etnozoología”. En Costa, Vargas y Santos 2009, 23-44.

Tebes, Mario y Atila Karlovich. 2010. Sisa Pallana. Antología de textos quichuas santiagueños. Buenos Aires: Eudeba.

Valero-Garcés, Blas y Norma Ratto. 2005. "Registros lacustres holocénicos en la puna de Chaschuil y El Bolsón de Fiambalá (dpto. Tinogasta, Catamarca): resultados preliminares”. En Actas del XVI Congreso Geológico Argentino, t. IV, editado por Raúl de Barrio, Eduardo Llambias, Ricardo Etcheverry y Marcelo Caballé, 163-170. La Plata: Universidad Nacional de La Plata.

Van Kessel, Juan y Dionisio Condori Cruz. 1992. Criar la vida. Trabajo y tecnología en el mundo andino. Santiago: Viviarium.

Van Kessel, Juan y Porfirio Enríquez Salas. 2002. Señas y señaleros de la Santa Tierra. Agronomía andina. Quito: Abya-Yala. 
Vidal de Battini, Berta. 1984. Cuentos y leyendas populares de la Argentina, t. VIII. Buenos Aires: Ediciones Culturales Argentinas.

Vilá, Bibiana. 2012. Camélidos sudamericanos. Buenos Aires: Eudeba.

—. 2014. “Una aproximación a la etnozoología de los camélidos andinos”. Etnoecológica 10: 1-16.

Wawrzyk, Ana y Bibiana Vilá. 2013. “Children's Values and Attitudes about the Wild Vicuña (Vicugna vicugna) in Andean Argentina”. Journal of Ecological Anthropology 16 (1): 27-42. http://hdl.handle.net/11336/27188

Yacobaccio, Hugo. 2009. “The Historical Relationship between People and the Vicuña”. En The Vicuña. Theory and Practice of Community-Based Wildlife Management, editado por Iain Gordon, 7-20. Townsville: Springer. 